\title{
Laparoscopy in the surgical management of the non-palpable testis
}

\author{
Javier Castillo-Ortiz ${ }^{1}$, Luis Muñiz-Colon ${ }^{1}$, Karina Escudero ${ }^{2}$ and Marcos Perez-Brayfield ${ }^{1,2}$ * \\ ${ }^{1}$ Division of Urology, University of Puerto Rico, San Juan, PR, USA \\ 2 Division of Urology, Inter-American Hospital for Advanced Medicine, Caguas, PR, USA
}

\section{Edited by:}

Miguel Alfedo Castellan, University of Miami, USA

Reviewed by:

Ricardo González, Auf der Bult Kinder und Jugendkrankenhaus, Germany

Miguel Alfedo Castellan, University of

Miami, USA

Marc Cendron, Harvard Medical

School, USA

\section{${ }^{*}$ Correspondence:}

Marcos Perez-Brayfield, Division of Urology, Medical Sciences Campus, University of Puerto Rico, P.O. Box 365067, San Juan, PR 00936-5067, USA

e-mail:mperezb1@yahoo.com
Introduction: To demonstrate that laparoscopic intervention should be considered as the initial surgical approach in the management of the non-palpable testis (NPT).

Methods: From 2007 to 2011, 100 testicular units underwent same surgeon laparoscopic management for NPT. Diagnostic laparoscopy was performed in all NPT and intra-abdominal testes (IAT) were managed by laparoscopic orchiopexy if low, laparoscopic Fowler-Stephens technique if high, and laparoscopic orchiectomy if atrophic. Percutaneous access to the abdomen was performed in most cases and laparoscopic management was performed with three $5 \mathrm{~mm}$ ports. We compared patient's age, race, pre/post-operative exam, preoperative work up, and IAT location upon laparoscopic intervention with surgical outcome. Fisher's exact test for two independent proportions was used for statistical analysis and reported our results.

Results: One hundred testicular units underwent diagnostic laparoscopy for NPT. All patients were from Puerto Rican descent. 55.0\% were found to be intra-abdominal and were subdivided into groups according to surgical intervention. Mean post-operative follow-up was 24 months. Patients 24 months of age or younger undergoing diagnostic laparoscopy for NPT had a statistically significant probability of resulting in successful laparoscopic orchiopexy as opposed to laparoscopic orchiectomy due to an atrophied IAT $(n=55$ testicular units, $p<0.05)$. No laparoscopic related complications were reported.

Conclusion: Our findings support the use of an initial laparoscopic approach in the NPT as the majority of these patients will have IAT, avoiding unnecessary inguinal and scrotal explorations. We also recommend that patients with IAT should undergo laparoscopic orchiopexy prior to 2 years of age to increase probability of successful management. Further studies focusing in patients with NPT are needed in the future to confirm our findings.

Keywords: non-palpable testis, laparoscopy, orchiopexy, cryptorchidism

\section{INTRODUCTION}

The undescended testis (UDT) is one the most common congenital abnormalities found in newborn males, affecting up to $4 \%$ of full term newborns and up to $45 \%$ of pre-term males (1). Of these, $20 \%$ of UDT's are reported as being non-palpable testis (NPT) to the examiner (2). The NPT can be non-present, atrophic, or have a failure to descend and be found in a high scrotal, inguinal, or intraabdominal location (IAT). Most series report that approximately $20-40 \%$ of non-palpable testes are intra-abdominal in location (38). There are well-established risk factors for UDT with the most frequently reported being low birth weight and short gestational period, along with the known associations of multiple congenital syndromes. More recently, theories have focused on environmental, geographical, and ethnic factors influencing the development of UDT (1).

Laparoscopic orchiopexy has become the preferred approach for the management of the NPT. To our knowledge, there are no reports on the incidence, diagnosis, and management of the NPT in the Puerto Rican population. We aim to demonstrate that laparoscopic intervention should be considered as the initial approach in the NPT.

\section{MATERIALS AND METHODS}

From August 2007 to November 2011, 100 testicular units underwent same surgeon diagnostic laparoscopy for NPT. Patients' ages ranged from 5 to 144 months, with a mean age of 53.0 months. All patients were Puerto Rican in descent. Prior to surgical intervention, patients were carefully examined again after general anesthesia induction to confirm that the testes were non-palpable. Patients were placed in slight Trendelenburg position with rotation of the bed away from the affected side. Percutaneous access to the abdomen using the Veress needle technique was used in most patients $(96 \%$ of patients). An umbilical $5 \mathrm{~mm}$ trocar was placed under direct vision, followed by two $5 \mathrm{~mm}$ trocars in standard laparoscopic fashion. Diagnostic laparoscopy was performed in all NPT. If testicular vessels were seen entering the internal inguinal ring, inguinal, or scrotal exploration was performed. If laparoscopy 
revealed an IAT, the testicle was classified as low $(<2 \mathrm{~cm}$ from the IIR) or high ( $\geq 2 \mathrm{~cm}$ from the IIR); laparoscopic orchiopexy was performed if low, laparoscopic one- or two-staged FowlerStephens technique (FSO) if high, or laparoscopic orchiectomy if atrophic, as previously described by Papparella et al. (9). Laparoscopic orchiopexy was performed using the Prentiss maneuver in all cases. Orchiectomy specimens were sent for histological examination.

All patients were followed post-operatively at 3 weeks, 3 and 6 months thereafter for a mean post-operative follow-up of 24 months and findings noted included: surgical site infections, post-operative testicular location, and testicular size, measured at the time of surgery and compared to the normal contralateral testis on follow-up by a single surgeon. Complications were divided into intra-operative and long-term. We compared patients' age, pre- and post-operative exam, pre-operative work up, and IAT location upon laparoscopic intervention with surgical outcome. Fisher's exact test for two independent proportions was used for statistical analysis and our results reported. Institutional Review Board approval was obtained prior to the initiation of this study.

\section{RESULTS}

Diagnostic laparoscopy findings are presented on Table 1. Fiftyfive testicular units $(55.0 \%)$ were found to be intra-abdominal (48.9\% right, $40.0 \%$ left, $11.1 \%$ bilateral) and were divided into two groups according to surgical intervention. Laparoscopic orchiectomy was performed in 7 testicular units due to intra-operative findings of an atrophied IAT (patient mean age: 84 months, range $24-144$ months). Laparoscopic orchiopexy was performed in 48 testicular units (patient mean age: 23 months, range 5-84 months). Of the laparoscopic FowlerStephens Orchiopexies, one stage-FSO was applied to 6 testicular

Table 1 | Findings upon diagnostic laparoscopy.

\begin{tabular}{lc}
\hline Findings & Number of testis \\
\hline Vessels/vas entering IIR* & 38 \\
Agenesis (no vessels identified) & 3 \\
IAT $<2 \mathrm{~cm}$ IIR & 41 \\
IAT $>2 \mathrm{~cm}$ IIR & 7 \\
Intra-abdominal blind-ending vessels & 4 \\
Atrophic IAT & 7 \\
\hline${ }^{*}$ All patients with NPT and with vessels/vas entering the IIR on laparoscopy were \\
found to be testicular nubbins and underwent orchiectomy through subsequent \\
scrotal exploration.
\end{tabular}

units (mean age 18 months, range $8-84$ months), two-staged-FSO was applied to 1 testicular unit (first stage at 6 months; second stage at 12 months). Complications are shown on Table 2. We found $100 \%$ (48/48) of testicular units, which underwent laparoscopic orchiopexy presented with adequate size post-operatively; only one patient underwent two-staged-FSO and presented with adequate size post-operatively; $83.3 \%$ (5 out of 6 ) testicular units, which underwent one stage-FSO presented with adequate testicular size post-operatively. The latter patient, which underwent one stage-FSO, developed a scrotal wound infection post-operatively and subsequently developed left testicular atrophy on followup. High riding scrotal testes were found in four patients (one patient younger than 24 months and three patients with 24 months of age and older). Although it can be noted that a tendency exists in patients older than 24 months undergoing laparoscopic orchiopexy will result in a testis in a high riding scrotal position, this finding did not reach statistical significance ( $n=48$ testicular units, $p=0.61$ ) (Figure 1). No intra-operative laparoscopic related complications were reported in our series and no complications relating to diagnostic laparoscopy were reported.

Patients with 24 months of age or younger who underwent diagnostic laparoscopy for NPT had a statistically significant probability of resulting in successful laparoscopic orchiopexy

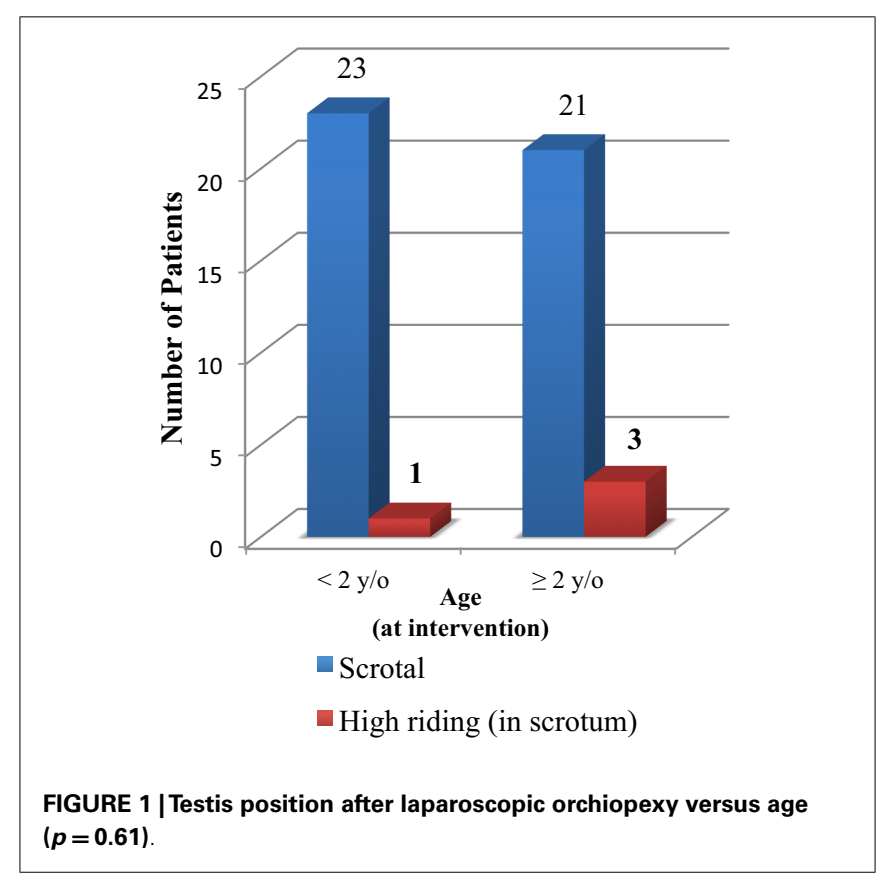

Table 2 | Distribution of complication rates.

\begin{tabular}{|c|c|c|c|c|c|}
\hline & High riding & Infection & Atrophy & Total complication rate & Total success rate \\
\hline Diagnostic laparoscopy & - & 0 & - & $0 \%(0 / 45)$ & $100 \%(45 / 45)$ \\
\hline Laparoscopic orchiopexy & 3 & 0 & 0 & $6.2 \%(3 / 48)$ & $94 \%(45 / 48)$ \\
\hline $1 \mathrm{FSO}$ & 1 & \multicolumn{2}{|c|}{1 (infection and atrophy in same patient) } & $33.3 \%(2 / 6)$ & $67 \%(4 / 6)$ \\
\hline $2 \mathrm{FSO}$ & 0 & 0 & 0 & $0 \%(0 / 1)$ & $100 \%(1 / 1)$ \\
\hline Total & $7 \%(4 / 55)$ & $1 \%(1 / 100)$ & $1.8 \%(1 / 55)$ & $5 \%(5 / 100)$ & $95 \%(95 / 100)$ \\
\hline
\end{tabular}




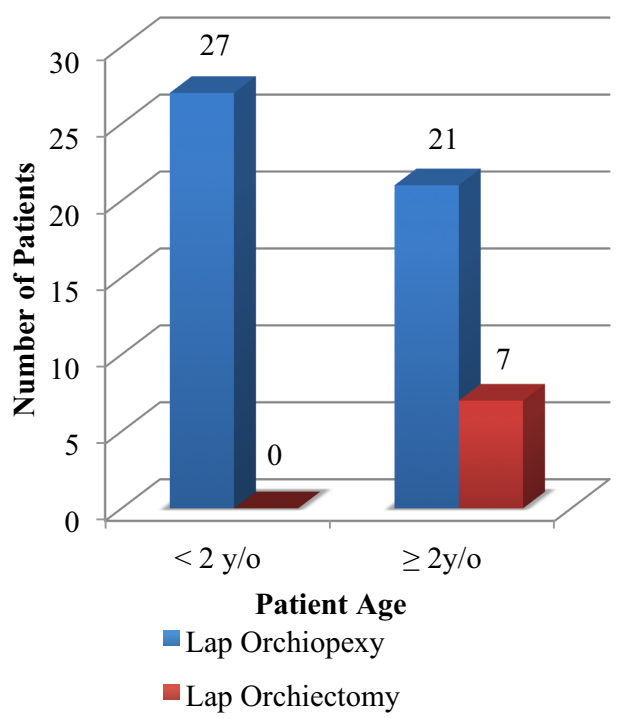

FIGURE 2 | Patient's age versus laparoscopic intervention $(p<0.05)$

as opposed to resulting in laparoscopic orchiectomy due to an atrophied IAT ( $n=55$ testicular units, $p<0.05)$ (Figure 2).

\section{DISCUSSION}

There is great variability on published literature on UDT regarding the incidence of IAT in NPT, in which most range from 20 to $40 \%$ (3-8). Genetics, geographical differences, environmental factors, race, and ethnicity have been proposed as possible factors affecting the rates of UDT. This variability on UDT rate may be in part explained by the heterogeneity of studied populations, that group genetic, ethnic, and geographically diverse populations in the same studied cohorts (1). In addition, a recent literature review on the frequency of UDT amongst boys from birth to adolescence demonstrated that only 6 of $46(13 \%)$ of studies recorded ethnicity. The majority of the reported studies ( 40 of $46,87 \%$ ) did not take ethnicity into account (1). Our study groups a cohort of patients and found an increased incidence of IAT (55\%) as compared to other published studies. As our studied population includes patients of similar racial background, one might suggest that race plays a significant role in the pathophysiology of the UDT.

Despite numerous publications regarding the management of the NPT, the debate on the proper initial surgical approach on this common urological condition continues. Even though the laparoscopic management has gained widespread approval over the last several years, opponents to this approach refer that the majority of NPT are extra-abdominal and can be managed through a scrotal or inguinal incision without exposing the patient to the risks of an unnecessary laparoscopic procedure $(2-4,9)$. The lower incidence of IAT in the literature is used by the proponents of a scrotal/inguinal approach to argue that up to $80 \%$ of laparoscopic interventions are unnecessary. As noted before, our incidence of IAT was higher than other published studies. This finding supports the use of an initial laparoscopic approach in our patient population as more than half of patients with
NPT were found to be IAT (55\%), avoiding scrotal or inguinal explorations in more than half of our studied population. Additionally, laparoscopic findings such as the absence of testicular vessels, which suggest testicular agenesis and intra-abdominal blind-ending vessels, avoided further abdominal, inguinal, and scrotal explorations in an additional $7 \%$ of patients. Taking this into consideration, initial laparoscopic intervention as a diagnostic tool in our patient population was beneficial to $62 \%$ of patients, as it provided relevant anatomic information that directed further surgical intervention. Similar results were demonstrated in other published data where diagnostic laparoscopy was beneficial to up to $73 \%$ of patients avoiding other unnecessary surgical approaches (9). These findings emphasize the decision to use laparoscopy as the initial surgical intervention in the NPT.

We also demonstrated that patients 24 months of age or younger undergoing diagnostic laparoscopy for NPT had a statistically significant probability of resulting in successful laparoscopic orchiopexy as opposed to resulting in laparoscopic orchiectomy due to an atrophied IAT. This finding gives importance to early diagnosis and treatment in the patient with UDT prior to 2 years of age. Spontaneous decent is felt to be complete in most patients by 6 months of age $(10,11)$. The above findings have let us to recommend treatment of the patient with NPT as early as 6 months but prior to 24 months of age.

Our series reported a $94 \%$ success rate in laparoscopic orchiopexy and an $85.7 \%$ success rate in laparoscopic FSO; results comparable to most published series and literature reviews, which report success rates ranging from 91.3 to $100 \%$ in laparoscopic orchiopexy (12-17) and 66.7 to $100 \%$ success in laparoscopic Fowler-Stephens orchiopexy $(2,12,17,18)$. We reported a $1 \%$ wound infection rate (1/100 laparoscopic interventions), attributed to a scrotal wound infection after a laparoscopic one-staged-FSO, a complication comparable to that of an inguinal or scrotal approach to the UDT, which report up to $3.3 \%$ of wound infections (19). We reported no intra-operative laparoscopic complications with almost all patients undergoing percutaneous access to the abdomen. Our data adds to recent studies that report no difference in complication rate between percutaneous and open Hassan technique in the pediatric population (20-22). Reports of complications regarding high riding testis after a single stage laparoscopic orchiopexy range from 0 to $8.7 \%(13,17,21,23)$, consistent with a $6.2 \%$ complication rate in our studied population. High riding testis after FSO ranges from 0 to $7.4 \%$ in reported series $(13,17,21)$; our series reports one patient with improper scrotal position after FSO resulting in 14.3\%. Lastly, our data demonstrates an atrophy rate of 0 and $14.3 \%$ in laparoscopic orchiopexy and FSO groups, respectively; consistent with atrophy rates in the literature of $0-2.2$ and $4.3-22.2 \%$ in laparoscopic orchiopexy and FSO groups, respectively $(13,17,21,24)$.

Several limitations are noted in our study. This is a retrospective cohort study based on a multi-institutional, single surgeon experience, possibly giving way to selection bias in our study. Even though testicular size was measured by a single surgeon in the operative setting and during follow-up and compared to the normal, contralateral testis for adequate size, this is a subjective appraisal of testicular size. We agree that testicular measurement 
by ultrasound offers a more precise and objective assessment and can be used as a confirmatory test to our clinical evaluation. Many of our patients are referred from other institutions after 12 months of age, which explains why our age group is higher than most published series and our elevated orchiectomy rate. In our series, only seven patients underwent Fowler-Stephens orchiopexy, and only one patient underwent a two-staged Fowler-Stephens orchiopexy, making it difficult to reach conclusion on this limited number of patients. Longer follow-up is needed to evaluate important outcomes such as infertility and risk of testicular malignancy later in life. Finally, to our knowledge, this is the first study, which has reported on the findings regarding the NPT in the Puerto Rican population.

In conclusion, our findings support the use of an initial laparoscopic approach in patients with NPT as the majority of these patients will have IAT, avoiding unnecessary inguinal and scrotal explorations. We also recommend that patients with IAT should undergo laparoscopic orchiopexy prior to 2 years of age to increase probability of successful management.

\section{REFERENCES}

1. Sijstermans K, Hack WW, Meijer RW, van der Voort-Doedens LM. The frequency of undescended testis from birth to adulthood: a review. Int J Androl (2008) 32:1-11. doi:10.1111/j.1365-2605.2007.00770.x

2. Esposito C, Garipoli V. The value of 2-step laparoscopic Fowler-Stephens orchiopexy for intraabdominal testes. J Urol (1997) 158:1952-4. doi:10.1016/ S0022-5347(01)64189-2

3. García Palacios M, Somoza I, Vela D. Non-palpable testes: laparoscopic or inguinal approach? Cir Pediatr (2009) 22:69-71. Available from: http://www. secipe.org/coldata/upload/revista/2009_22-2_69-71.pdf

4. Snodgrass WT, Yucel S, Ziada A. Scrotal exploration for unilateral nonpalpable testis. J Urol (2007) 178:1718-21. doi:10.1016/j.juro.2007.05.089

5. Esposito C, Caldamone AA, Settimi A, El-Ghoneimi A. Management of boys with non palpable undescended testis. Nat Clin Pract Urol (2008) 5:252-60. doi:10.1038/ncpuro1102

6. Kirsch AJ, Escala J, Duckett JW, Smith GH, Zderic SA, Canning DA, et al. Surgical management of the nonpalpable testis: the Children's Hospital of Philadelphia experience. J Urol (1998) 159:1340-3. doi:10.1097/00005392-199804000-00086

7. Humphrey GM, Najmaldin AS, Thomas DF. Laparoscopy in the management of the impalpable undescended testis. Br J Surg (1998) 85:983-5. doi:10.1046/j. 1365-2168.1998.00748.x

8. Das S. Laparoscopic evaluation of nonpalpable testes. Urology (1991) 37:460-2. doi:10.1016/0090-4295(91)80111-J

9. Papparella A, Romano M, Noviello C, Cobellis G, Nino F, Del Monaco C, et al. The value of laparoscopy in the management of non-palpable testis. J Pediatr Urol (2010) 6:550-4. doi:10.1016/j.jpurol.2009.12.010

10. Heyns CF. The gubernaculum during testicular descent in the human fetus. J Anat (1987) 153:93-112.

11. Barthold JS. Abnormalities of the Testis and Scrotum and Their Surgical Management, Campbell-Walsh Urology. 10th ed. Philadelphia: Saunders (2012). p. $3557-60$.
12. Chang B, Palmer LS, Franco I. Laparoscopic orchidopexy: a review of a large 22 clinical series. BJU Int (2001) 87:490-3. doi:10.1046/j.1464-410X.2001.00100.x

13. El-Anany F, Gad El-Moula M, Abdel Moneim A, Abdallah A, Takahashi M, Kanayama H, et al. Laparoscopy for impalpable testis: classification based management. Surg Endosc (2007) 21:449-54. doi:10.1007/s00464-006-9003-0

14. Esposito C, Vallone G, Settimi A, Gonzalez Sabin MA, Amici G, Cusano T. Laparoscopic orchiopexy without division of the spermatic vessels: can it be considered the procedure of choice in case of intraabdominal testis? Surg Endosc (2000) 14:658-60. doi:10.1007/s004640000107

15. Poppas DP, Lemack GE, Mininberg DT. Laparoscopic orchiopexy: clinical experience and description of technique. J Urol (1996) 155:708-11. doi:10.1097/ 00005392-199602000-00098

16. Radmayr C, Oswald J, Schwentner C, Neururer R, Peschel R, Bartsch G. Longterm outcome of laparoscopically managed nonpalpable testes. J Urol (2003) 170:2409-11. doi:10.1097/01.ju.0000090024.02762.3d

17. Baker LA, Docimo SG, Surer I, Peters C, Cisek L, Diamond DA, et al. A multiinstitutional analysis of laparoscopic orchidopexy. Br J Urol (2001) 87:484-9. doi:10.1046/j.1464-410X.2001.00127.x

18. El-Gohary A. Two stage laparoscopic Fowler-Stephens procedure for high abdominal testis. Saudi Med J (2003) 24:30-3.

19. Bassel YS, Scherz HC, Kirsch AJ. Scrotal incision orchiopexy for undescended testis with or without a patent processus vaginalis. J Urol (2007) 177:1516-8. doi:10.1016/j.juro.2006.11.075

20. Esposito C, Lima M, Mattioli G, Mastroianni L, Centonze A, Monguzzi GL, et al. Complications of pediatric urological laparoscopy: mistakes and risks. J Urol (2003) 169:1490-2. doi:10.1097/01.ju.0000055256.43528.f6

21. Yanke BV, Horowitz M. Safety of the Veress needle in pediatric laparoscopy. J Endourol (2007) 21:695-7. doi:10.1089/end.2006.9950

22. Passerotti CC, Nguyen HT, Retik AB, Peters CA. Patterns and predictors of laparoscopic complications in pediatric urology: the role of ongoing surgical volume and access techniques. J Urol (2008) 180:681-5. doi:10.1016/j.juro.2008. 04.042

23. Lindgren BW, Darby EC, Faiella L, Brock WA, Reda EF, Levitt SB, et al. Laparoscopic orchiopexy: procedure of choice for the nonpalpable testis? J Urol (1998) 159:2132-5. doi:10.1097/00005392-199806000-00137

24. Jordan W. Laparoscopic single stage and staged orchiopexy. J Urol (1994) 152:1249-52.

Conflict of Interest Statement: The authors declare that the research was conducted in the absence of any commercial or financial relationships that could be construed as a potential conflict of interest.

Received: 24 January 2014; accepted: 24 March 2014; published online: 08 April 2014. Citation: Castillo-Ortiz J, Muñiz-Colon L, Escudero K and Perez-Brayfield M (2014) Laparoscopy in the surgical management of the non-palpable testis. Front. Pediatr. 2:28. doi: 10.3389/fped.2014.00028

This article was submitted to Pediatric Urology, a section of the journal Frontiers in Pediatrics.

Copyright (c) 2014 Castillo-Ortiz, Muñiz-Colon, Escudero and Perez-Brayfield. This is an open-access article distributed under the terms of the Creative Commons Attribution License (CC BY). The use, distribution or reproduction in other forums is permitted, provided the original author(s) or licensor are credited and that the original publication in this journal is cited, in accordance with accepted academic practice. No use, distribution or reproduction is permitted which does not comply with these terms. 